\title{
ANÁLISE DA POLÍTICA POR PAGAMENTO POR SERVIÇOS AMBIENTAIS COMO UM INSTRUMENTO PARA SUSTENTABILIDADE SOCIOAMBIENTAL
}

\author{
Gabriel Spínola Garcia Távora ${ }^{1}$ \\ Antônio Soares da Silva ${ }^{2}$ \\ Ana Paula Dias Turetta ${ }^{3}$
}

\begin{abstract}
Resumo: A mudança do paradigma ambiental mostrou a necessidade de se repensar as práticas de apropriação dos sistemas naturais, e, também, a criação de novos instrumentos que incentivem a preservação desses sistemas. Foi visando justamente à recuperação dos sistemas degradados que surgiram os programas de pagamento por serviços ambientais (PPSA). $\mathrm{O}$ objetivo do presente trabalho foi analisar a temática do pagamento por serviços, enquanto uma política ambiental voltada para a promoção da sustentabilidade socioambiental. Ao longo do trabalho, foi feita uma discussão sobre o conceito de desenvolvimento sustentável e como ele implica na política de pagamento por serviços ambientais. Além disso, foi apresentado um panorama dos programas implementados no Brasil. Observa-se que os programas de pagamento por serviços ambientais no Brasil ainda estão se consolidando.
\end{abstract}

Palavras-chave: Serviços ecossistêmicos; Política ambiental; Sustentabilidade;

Desenvolvimento sustentável

\section{ANALYSIS OF POLICY FOR PAYMENT FOR ENVIRONMENTAL SERVICES POLICY AS A TOOL FOR ENVIRONMENTAL SUSTAINABILITY}

\begin{abstract}
The change of the environmental paradigm has shown the need to rethink the use of practices of natural systems, and also the creation of new instruments to encourage the preservation of these systems. Thus, the payment for environmental services programs was created aimed at the recovery of the degraded ecosystems. The goal of this paper is to analyze the issue of payment for services as an environmental policy aimed at promoting environmental sustainability. In this paper was discussed the concept of sustainable development and how it influences the payment for environmental services. Besides that, was presented an overview about the payment for environmental services programs in Brazil. It was noted that, in Brazil, the payment for environmental services programs are still not consolidated as a policy to improve the social well-being and also encourage the environmental preservation.
\end{abstract}

Keywords: Ecosystem services; Environmental politics; Sustainability; Sustainable development

\section{ANÁLISIS DE LA POLÍTICA DE PAGO POR SERVICIOS AMBIENTALES COMO UN INSTRUMENTO PARA LA SOSTENIBILIDAD SOCIOAMBIENTAL}

Resumen: El cambio del paradigma ambiental mostró la necesidad de repensar las prácticas de apropiación de los sistemas naturales, y también la creación de nuevos instrumentos que incentiven la preservación de esos sistemas. Fue precisamente para la recuperación de los

\footnotetext{
1 Doutorando do em Geografia na Universidade do Estado do Rio de Janeiro. Contato: gabriel_spinola@hotmail.com

${ }_{2}^{2}$ Prof. Adjunto do Departamento de Geografia Física do Instituto de Geografia da UERJ Rio de Janeiro/RJ Brasil. Contato: antoniossoares@gmail.com

${ }^{3}$ Pesquisadora A da Embrapa Solos - Rio de Janeiro, RJ Contato: anaturetta@cnps.embrapa.br
} 
sistemas degradados que surgieron los programas de pago por servicios ambientales (PPSA). El objetivo del presente trabajo fue analizar la temática del pago por servicios, mientras que una política ambiental orientada a la promoción de la sustentabilidad socio ambiental. A lo largo del trabajo, se hizo una discusión sobre el concepto de desarrollo sostenible y cómo implica la política de pago por servicios ambientales. Además, se presentó un panorama de los programas implementados en Brasil. Se observa que los programas de pago por servicios ambientales en Brasil todavía se están consolidando

Palabras clave: Servicios ecosistémicos; Política ambiental; Sostenibilidad; Desarrollo sostenible

\section{INTRODUÇÃO}

A temática ambiental tem, cada vez mais, conquistado notoriedade nos debates da sociedade, principalmente a partir da década de 1960, quando se verifica o desenvolvimento de estudos e o surgimento de um pensamento epistemológico que tomou o ambiente como objeto de reflexão. Tal pensamento vai além do que se compreende como ecologia, busca abarcar toda a complexidade do mundo atual. Leff (2006) discorre sobre como a crise ambiental contribuiu para a discussão em torno dessa questão e para o desenvolvimento de um pensamento epistemológico pautado na questão ambiental

Esta crise se apresenta a nós como um limite no real, que ressignifica e reorienta o curso da história: limite do crescimento ecológico e populacional; limite dos desequilíbrios ecológicos e das capacidades de sustentação da vida; limite da pobreza e da desigualdade social. Mas também crise do pensamento ocidental [...](LEFF, 2007, p. 191).

A mudança do paradigma ambiental mostrou a necessidade de se repensar as práticas de apropriação dos sistemas naturais e também a criação de novos instrumentos que incentivem a preservação desses. A criação desses instrumentos resultará em políticas ambientais que têm por objetivo reduzir os impactos negativos resultantes da ação antrópica sobre os sistemas naturais (LUSTOSA et. al., 2003).

Derani e Souza (2013) afirmam que as políticas ambientais podem ser divididas em dois grupos, que são: os instrumentos de comando e de controle e os instrumentos econômicos. Os instrumentos de comando e controle são mecanismos voltados para controle/monitoramento direto sobre agentes poluidores. A partir do uso desses, o Estado pode exercer a regulação sobre as atividades dos agentes econômicos, impor restrições ao uso dos recursos e definir os níveis de poluição (DERANI e SOUZA, 2013).

Os instrumentos econômicos, também conhecidos como instrumentos de mercado, têm por objetivo fazer com que os agentes poluidores internalizem os custos ambientais que antes não seriam contabilizados (LUSTOSA et. al., 2003). Segundo Derani e Souza (2013, p.252), 
esses instrumentos "se baseiam na crença de que o mercado pode ser usado a fim de fornecer incentivos para guiar o comportamento humano”.

Dessa forma, o Estado atuaria como um ente regulador, fiscalizador, mediador de possíveis conflitos e determinaria a alocação de recursos (ANDRADE e FASIABEN). Existem diversas formas de se aplicar os instrumentos econômicos, e, por isso, de acordo com Jodas e Portanova (2014), faz-se necessário que as escolhas políticas estejam ligadas diretamente às necessidades sociais.

A crescente apropriação dos recursos naturais tem impactado cada vez mais os ecossistemas e agravado as condições sociais e ambientais. Dessa forma, a preservação dos serviços providos pelos diferentes ecossistemas tem sido alvo de preocupação tanto de governos como de instituições privadas. Tendo por objetivo a preservação dos serviços prestados pelos ecossistemas, as políticas de pagamento por serviços ambientais têm se difundido como um instrumento econômico complementar às políticas de comando e de controle.

O objetivo do presente trabalho é analisar a temática do pagamento por serviços enquanto uma política ambiental voltada para a promoção da sustentabilidade socioambiental.

\section{POR UMA SUSTENTABILIDADE SOCIOAMBIENTAL}

A partir da segunda metade do século XX, o mundo se deparou com um processo de contestação, por parte de grupos de ambientalistas, à proposta de desenvolvimento que fora imposta pelas diferentes matrizes hegemônicas da época. Durante anos, tanto os modelos de desenvolvimento liberal capitalista quanto o socialista buscaram um projeto civilizatório em que o urbano e o industrial eram considerados símbolos de desenvolvimento (PORTO GONÇALVES, 2004).

A conceituação de desenvolvimento, de acordo com Pizzi (2005), não é exclusividade dos economistas do século XIX e XX. De acordo com o autor (op. cit.), essa ideia já estava presente na Europa medieval e tinha como pressuposto a ideia de um ciclo, com começo, seguido por um ápice e, posteriormente, um declínio. Já no século XVII, com o estabelecimento da ciência positivista, o termo desenvolvimento ficou associado à ideia de "progresso sistemático". Por fim, com o estabelecimento da racionalidade moderna, especialmente após a Segunda Guerra Mundial, o conceito passou a ser utilizado como sinônimo de crescimento, avanço e prosperidade.

As políticas no período pós-guerra, como, por exemplo, o modelo keynesiano e as políticas de bem-estar social, que foram adotadas pelos países desenvolvidos, contribuíram 
para a expansão da teoria de desenvolvimento econômico. Saul (2003) nos mostra que os países hegemônicos utilizaram um discurso que apontava que os países ditos "atrasados" só alcançariam o progresso se seguissem as etapas de desenvolvimento indicadas por eles. Ainda segundo o autor (op. cit.), os países desenvolvidos propagavam que as resistências por parte dos setores arcaicos dos países subdesenvolvidos é que atrasavam o processo de modernização ${ }^{4}$.

De acordo com Porto-Gonçalves (2004) e Rua (2007), a concepção de desenvolvimento adotada quase que de forma homogênea tinha como base a ideia de que o desenvolvimento era sinônimo de crescimento econômico e melhoria da qualidade de vida. Esse ideário epistemológico tem suas raízes estabelecidas no iluminismo. A teoria iluminista acreditava que as condições sociais e naturais podiam ser melhoradas a partir do uso da razão e da ciência. Logo, a noção de progresso também está ligada ao desenvolvimento técnico e como este condiciona o bem-estar da população a partir da (re)produção dos seus espaços.

Furtado (2000) afirma que essa ideia de desenvolvimento acaba criando perspectivas distintas. De um lado, temos a noção do desenvolvimento como eficácia da acumulação e da técnica de um sistema social que contribui com o grau de satisfação das necessidades humanas. O progresso técnico é apresentado como um instrumental para superação das mazelas sociais, adversidades ambientais e também é responsável pela reconstrução constante do desenvolvimento. Já a outra perspectiva mostra que o progresso técnico possibilita e reafirma o processo de acumulação, e, por conseguinte, a reprodução da sociedade capitalista.

A adoção de tal modelo de desenvolvimento, de acordo com Rua (2007, p.147), contribuiu para a manifestação de desigualdades sociais e espaciais, uma vez que esse modelo continua sendo "considerado um processo (natural) que cria o novo, destruindo o velho, e em que o declínio e a destruição são partes de um ciclo". Além disso, esse modelo não apenas levou para todos os cantos do mundo as lógicas industriais, consumista, utilitarista e produtivista, como também foi responsável pela construção de uma visão dicotômica na relação homem e natureza (RUA, 2007).

Essa relação começa tomar corpo ainda no século XVII, com as ideias positivistas, e após a primeira Revolução Industrial se tornar a base do pensamento moderno. A partir do momento que o homem começou a se enxergar como o indivíduo transformador do espaço, ele começou a vislumbrar a natureza como um recurso disponível.

Portanto, a natureza, que antes era vista como algo mítico/sacralizado, a partir de uma visão integrada do homem e da natureza, passou a ser entendida sob uma ótica utilitarista. $\mathrm{Ou}$

\footnotetext{
${ }^{4}$ De acordo com Rua (2007, p.152): "Modernização seria sinônimo de ocidentalização e conduziria ao desenvolvimento e ao progresso".
} 
seja, a natureza começou a ser percebida/concebida como um bem, uma mercadoria ou um produto que é condicionador e condicionante para o desenvolvimento econômico (PORTOGONÇALVES, 2004; RUA, 2007). Destarte, Porto-Gonçalves (op. cit.) aponta que os modelos de desenvolvimento propostos pelos grupos hegemônicos, tanto de direita como de esquerda, são modelos de dominação da natureza.

$\mathrm{Na}$ medida em que esse modelo de desenvolvimento foi se tornando cada vez mais hegemônico e se propagando para todas as partes do globo (ainda que com intensidades diferentes), a partir da década de 1950, suas problemáticas também começaram a se complexificar e atingir uma escala global (RUA, 2007).

Logo, para se alcançar o "progresso", era cada vez mais necessário a exploração de recursos naturais. Um exemplo disso é que, na década de 1950, o consumo mundial de energia cresceu dez vezes em relação ao século anterior, o que por sua vez exigiu uma exploração ainda maior das fontes energéticas (Oliveira 2012).

Por conta disso, os grupos de ambientalistas começaram a questionar o modelo de desenvolvimento vigente. Sachs (2002) afirma que a onda de conscientização ambiental ganhou mais notoriedade, principalmente, a partir de dois eventos, e são eles: a explosão da bomba atômica em Hiroshima e a aterrissagem do homem na Lua.

Esses dois eventos são importantes porque o primeiro mostra que a humanidade conseguiu tanto poder técnico que, eventualmente, poderia acabar com toda a vida do planeta. Desse modo, a opinião pública tornou-se consciente da limitação do capital da natureza e dos perigos decorrentes das agressões ao ambiente (SACHS, 2002).

A partir disso, percebemos que dois paradigmas que estavam fortemente presentes na sociedade começaram a ser repensados. O primeiro seria quanto à capacidade da ciência em dominar a natureza e o segundo, a crença ilimitada nas virtudes do progresso técnico (SACHS, 2002).

O movimento ambiental, que surge no início da década de 1960, trouxe um olhar mais crítico ao discurso desenvolvimentista preconizado e difundido na década anterior. Contudo, não foram somente os ambientalistas que estiveram preocupados com a questão ambiental. No final dos anos 1960, o Clube de Roma, preocupado com os níveis de consumo dos recursos não renováveis, encomendou aos cientistas do Massachusetts Institute of Technology (MIT) um estudo que pudesse indicar por quanto tempo poderiam ser mantidos os níveis de crescimento e consumo. Esse estudo ficou conhecido como The limits to growth (Os limites para o crescimento). Essa publicação teve como principal resolução a necessidade de se parar o crescimento econômico e populacional. Contudo, o que realmente mereceu destaque foi que, pela primeira vez, os recursos naturais são abordados a partir de uma visão de sistema 
fechado, e não aberto, como era de costume (PORTO GONÇALVES, 2004; SACHS 2002).

O estudo encomendado pelo Clube de Roma teve grande divulgação internacional e foi de suma importância, pois foi a primeira vez que os economistas do desenvolvimento começaram a discutir problemas que antes eram deixados de lado. Os resultados apresentados por esse trabalho tiveram influência nos debates apresentados na Primeira Conferência Mundial Sobre o Homem e o Meio Ambiente, realizada em Estocolmo, no ano de 1972 (OLIVEIRA, 2012; PORTO-GONÇALVES, 2004).

A Conferência de Estocolmo foi palco de um embate entre duas correntes de pensamento à época. De um lado, estavam os defensores do sistema, que buscavam manter o modelo de desenvolvimento a partir da reconstrução de estruturas e organizações com base em um movimento de porte mundial, mesmo que isso significasse a manutenção do ônus ambiental. De outro, um grupo de "pessimistas" que diziam que, se as taxas de crescimentos demográficos e econômicos fossem mantidas, em pouco tempo levariam a escassez de recursos. Esse segundo grupo chegou a sugerir o crescimento zero, contudo, essa ideia foi prontamente rechaçada (SACHS, 2002).

Essa conferência também tentou buscar, sem sucesso, um consenso entre os países centrais e periféricos no que diz respeito ao uso predatório dos recursos. Embora o conceito de desenvolvimento sustentável não tenha sido tratado, essa conferência foi importante para o surgimento da ideia de se resguardar uma parte da reserva do capital natural para gerações futuras, tendo como premissa um consumo mais equilibrado dos recursos naturais (SACHS, 2002; PORTO-GONÇALVES, 2004; RUA, 2007; OLIVEIRA, 2012).

Sob a chancela da ONU, os debates relativos às questões ambientais se mantiveram presentes na agenda global. Com a criação do Programa do Meio Ambiente das Nações Unidas (PNUMA), em 1972, e, posteriormente, com a criação da Comissão Mundial Sobre o Meio Ambiente e Desenvolvimento (CMMAD), pela Assembleia Geral da ONU, foram postos em prática diversos estudos e trabalhos que tinham por objetivo a proteção do meio ambiente. O principal trabalho publicado nesse período foi o relatório "Nosso Futuro Comum”, também conhecido como Relatório Brundtland (OLIVEIRA, 2012; FREITAS et. al. 2012).

Esse trabalho, publicado em 1987, definiu o conceito de desenvolvimento sustentável: "o desenvolvimento que satisfaz as necessidades presentes sem comprometer a capacidade das gerações futuras de suprirem suas próprias necessidades” (CMMAD, 1991, p. 7).

A principal meta do relatório era mostrar que o desenvolvimento poderia ser alcançado, desde que todos os países, especialmente os países periféricos, seguissem suas normas. Rua (2007) afirma que o desenvolvimento sustentável proposto pelo relatório, e que predominou 
até quase a virada do século, tinha como intenção manter os níveis de crescimento econômico e consumo, mas, para isso, diminuir as taxas de exploração dos recursos naturais por parte dos países em desenvolvimento.

Logo, esse "novo" modelo de desenvolvimento mantinha uma relação estreita com o velho discurso de desenvolvimento, mas sob uma ótica conservacionista de uso dos recursos. Essa noção de desenvolvimento sustentável é comumente utilizada como sinônimo de crescimento sustentável. Sobre isso, Daly (2004) mostra que o discurso de desenvolvimento sustentável, enquanto sinônimo de crescimento sustentável, é totalmente inviável. Para o autor (op. cit.), os ecossistemas desenvolvem-se, mas não crescem, por causa da finitude de matéria no planeta. Portanto, a lógica de desenvolvimento sustentável que se baseia no constante crescimento não é possível, já que os recursos são finitos.

A discussão de desenvolvimento sustentável apresentada no Relatório Brundtland teve grande repercussão mundial e foi amplamente debatida na Conferência das Nações Unidas Sobre o Meio Ambiente e o Desenvolvimento, realizada no Rio de Janeiro, em 1992. Contudo, foi somente na Rio+10 que o conceito de desenvolvimento sustentável começou a ser redefinido epistemologicamente.

Esse (re)pensar epistemológico teve como ponto de partida a possível quebra de acordos de solidariedade ambiental mundial por parte dos países periféricos, que estavam vivendo um recrudescimento das desigualdades sociais. Tal situação fez com que, nessa conferência, o centro do debate fossem temas como pobreza e desigualdade social (RUA, 2007).

Ainda de acordo com Rua (op.cit.), os critérios apresentados na Rio+10 para o “desenvolvimento" foram

[...] de equidade social, erradicação da pobreza, precaução, participação popular, responsabilidades comuns, porém diferenciadas, e o novíssimo conceito de governança, apontando claramente para o reconhecimento de novos interlocutores localizados na esfera pública, não estatal, cujo agente principal era a sociedade civil organizada, para além dos Estados nacionais. (RUA, 2007, p. 30)

Destarte, Leff (1999) mostra que o discurso do desenvolvimento sustentável não é homogêneo, ou seja, da mesma forma que ele é utilizado pelas correntes hegemônicas para garantir a manutenção do status quo, ele acaba sendo utilizado por correntes contrárias que buscam uma ruptura com o tipo de racionalidade vigente. Ainda de acordo com o autor (op. cit.), o desenvolvimento sustentável tem que buscar a equidade social, diversidade cultural e democracia participativa, e, para tal, deve criar uma racionalidade ambiental. A construção 
dessa racionalidade implica na construção de novas práticas sociais a partir de processos emancipatórios, reflexivos e complexos (LEFF, 1999 e 2007).

Para tanto, o desenvolvimento deve ser visto como uma construção cultural de cada grupo social e de cada territorialidade. Ao ser entendido como tal, o conceito de desenvolvimento liberta-se das amarras impostas pelo discurso elaborado pelos grupos hegemônicos. Embora essa construção seja feita na escala do local, ela não pode ser dissociada das escalas nacional e global (FONSECA, 2005; RUA 2007).

Portanto, o grande desafio do discurso a respeito do desenvolvimento sustentável é transcender o viés economicista do crescimento (in)sustentável que é imposto de cima para baixo. Deve-se criar novas formas para que os habitantes de cada lugar, a partir das suas interações multiescalares, busquem o seu desenvolvimento e as sustentabilidades socioambientais ${ }^{5}$.

\section{CONTEXTUALIZAÇÃo ACERCA DOS PROGRAMAS POR PAGAMENTO POR SERVIÇOS AMBIENTAIS}

A seguridade e as reais condições dos ecossistemas e as suas consequências diretas e indiretas para o bem-estar da humanidade ainda estão presentes na agenda de preocupações globais. Para tentar buscar respostas mais acuradas sobre tais questionamentos é que a ONU, em 2001, deu início ao projeto “A Avaliação Ecossistêmica do Milênio”. Esse projeto, que tinha como objetivo fornecer bases científicas para a gestão sustentável dos ecossistemas, foi conduzido até 2005 através de parcerias entre diversas instituições internacionais e com o suporte de vários governos. Até hoje, é considerado o principal trabalho de referência nos estudos acerca dos bens e serviços ecossistêmicos. De acordo com os resultados publicados pelo projeto, dos 24 serviços ecossistêmicos analisados, 15 estão em declínio, fazendo-se necessário a produção de novas pesquisas sobre o tema (ANDRADE e ROMEIRO, 2009; MEA, 2005; FISHER et. al., 2009).

Os resultados apresentados pela Avaliação Ecossistêmica do Milênio (MEA) mostram que os ônus ambientais estão relacionados diretamente à diminuição da qualidade de vida das pessoas, assim como comprometem a qualidade do bem-estar das gerações futuras (MEA, 2005). Para reverter o processo de degradação ambiental e social, faz-se necessário promover a proteção, o uso sustentável e a recuperação dos ecossistemas e, dessa forma, garantir a

\footnotetext{
${ }^{5} \mathrm{O}$ termo sustentabilidade socioambiental, apresentado por Moreira (2004), garante ao termo sustentabilidade ambiental, que significa sustentabilidade do ambiente natural e da biodiversidade, uma conotação mais social ao considerar os níveis de pobreza e os suportes sociais às populações de baixa renda. Além disso, o termo traz consigo uma preocupação com as condições de subsistência social, ao fazê-lo defende a biodiversidade como condição básica a subsistência.
} 
manutenção dos serviços ecossistêmicos que têm papel preponderante para o bem-estar dos homens.

O conceito de serviços ecossistêmicos não é novo, e, segundo Martín-Lopez e Montes (2008), Balvanera e Cotler (2007), ele surge no começo da década de 1980, em meio ao despertar em relação às questões ambientais e aos questionamentos acerca da capacidade do planeta de manter e produzir os bens necessários para a manutenção dos níveis de consumo da população. Além disso, o conceito de serviços ecossistêmicos tem sido trabalhado por diversos autores (BOYD e BANZHAF, 2007; DAILY, 1997; COSTANZA et.al. 1997; DE GROOT, et.al., 2002; WUNDER, 2005). A definição mais utilizada hoje em dia é da Avaliação Ecossistêmica do Milênio (MEA, 2005), que apresenta o conceito como sendo os benefícios que as pessoas obtêm dos ecossistemas. Aqui se incluem os serviços de abastecimento, de regulação e de bens culturais, que afetam diretamente as pessoas, além dos serviços de suporte que são necessários para manter os outros serviços.

Além do conceito de serviços ecossistêmicos, também encontramos na literatura o termo de serviços ambientais. Para muitos autores, esses conceitos podem ser aplicados como sinônimos (MAY e GELUDA, 2005; Wunder, 2005; ANDRADE e FASIABEN, 2009). Porém, para Agência Nacional de Águas (ANA, 2009) e Chomitz et al., (1999), os serviços ambientais são os benefícios resultantes das atividades antrópicas em favor dos sistemas ecológicos. Já Mattos (2013) afirma que todas as ações humanas sobre o sistema natural causam alguma externalidade, independentemente do tamanho do impacto. Essas externalidades podem gerar impactos negativos ou positivos. As externalidades positivas são chamadas de serviços ambientais. Utilizaremos, no trabalho, o termo serviços ambientais no lugar de serviços ecossistêmicos, porque, assim como Mattos (2011), entendemos que, mesmo nos sistemas ambientais muito pouco alterados, isso é, com alto grau de conservação, há, em algum grau, alguma externalidade decorrente da intervenção humana. Logo, os serviços ambientais são resultantes positivas desses sistemas.

É visando justamente à recuperação dos serviços degradados que os programas de pagamento por serviços ambientais (PPSA) surgem como uma alternativa para a promoção da sustentabilidade nas suas mais diversas dimensões (NOVAES, 2014).

O pagamento por serviços ambientais (PSA) pode ser considerado um instrumento relativamente novo, no que diz respeito às políticas ambientais, logo, o seu desenvolvimento teórico ainda está em constante aperfeiçoamento. Uma das mais difundidas definições de PSA é a de Wunder (2005), que o definiu como sendo

uma transação voluntária em que um serviço ambiental bem definido (ou um uso e ocupação do solo que assegure esse serviço) está sendo comprado por pelo menos um comprador; de pelo menos um provedor; se, e somente se, o 
provedor do serviço ambiental garantir a oferta desse serviço. (WUNDER, 2005, p. 3).

Para Murandian et. al. (2010), o objetivo do PSA é incentivar a geração de bens ambientais públicos e a mudança do comportamento coletivo e individual. Para que o objetivo do PSA seja alcançado, é necessária a transferência de recursos entre os atores sociais (provedor e o beneficiado) envolvidos.

Destarte, Wunder et. al. (2008) afirmam que, quando tratado como uma política de Estado, o pagamento por serviços ambientais se torna um mecanismo que auxilia a gestão ambiental e a inclusão social. Contudo, algumas condições básicas devem ser preenchidas para implementação e funcionamento dos programas de pagamento de serviços ambientais.

Antes da implementação do projeto, é necessário definir, com clareza, por quais serviços ambientais há uma demanda, estabelecer quais práticas contribuem para geração desse serviço, identificar se há uma disposição em pagar pelo beneficio gerado e criar um projeto e definir quem será o responsável pelo pagamento. Além disso, é necessário demarcar as áreas dos provedores e determinar os valores dos serviços. Por último, ainda é preciso que se estabeleçam os parâmetros utilizados para o monitoramento dos serviços ambientais e também para analisar os progressos sociais alcançados pelo projeto (MAY e GELUDA, 2005; WUNDER et.al., 2008).

Os serviços ambientais mais presentes nos programas de pagamento, segundo a literatura (ELOY et. al., 2013; MAY e GELUDA, 2005; PRADO, 2012; NOVAES, 2014), são os relacionados ao sequestro de carbono, regulação e qualidade dos recursos hídricos e manutenção da biodiversidade. O fornecimento desses serviços está diretamente relacionado às diferentes práticas de manejo executadas pelos provedores (ELOY et. al., 2013).

Os programas por pagamento por serviços ambientais (PPSA) podem ser categorizados de acordo com as formas de manejo empregadas. Eloy et. al. (2013), em seu trabalho, indicam quatro modalidades, a saber: de restrição de uso, de restauração, de valorização de práticas tradicionais e de transição.

Os PPSA de restrição de uso e de restauração têm por objetivo gerar serviços ambientais a partir da preservação de áreas florestais. Na modalidade restrição de uso, o agricultor recebe uma compensação para não desmatar as áreas florestadas que porventura seriam por ele utilizadas. Na segunda modalidade, o agricultor recebe uma contribuição para fazer uma recomposição da vegetação nas áreas desmatadas (ELOVOY et. al., 2013).

Os PPSA de valorização de práticas tradicionais e transição estão relacionados com os serviços ambientais gerados a partir das práticas humanas. O PPSA de valorização das 
práticas tradicionais tem por objetivo garantir a manutenção das práticas agroextrativistas, desde que estas não interfiram na geração dos serviços ambientais. Enquanto a modalidade de transição incentiva os pequenos agricultores a adotarem práticas mais conservacionistas (ELOVOY et. al., 2013).

O PSA, enquanto política ambiental, vai em direção contrária às políticas vigentes, pois, atualmente, ainda é empregada a premissa do poluidor-pagador ${ }^{6}$. O pagamento por serviços ambientais (PSA) é instrumento legal que trabalha com a lógica do provedor-recebedor (MORAES, 2012). O princípio do provedor-recebedor se baseia na premissa de que os custos e oportunidades gerados pelos serviços ambientais deverão ser mantidos pelos beneficiários e usuários dos serviços, e os provedores dos serviços deverão ser compensados economicamente. Esse modelo tem sido reconhecido como mais eficiente e eficaz no controle aos danos ambientais, se comparado com o do poluidor-pagador (MORAES, idem; ANA, 2009).

Assim, o PSA surge como um instrumento que visa não só ao melhoramento da qualidade ambiental, já que promove a preservação dos ambientes naturais, como também objetiva a melhoria das condições sociais, já que tem como princípio a transferência econômica entre os provedores dos serviços ambientais, que, na maioria das vezes, são os pequenos proprietários rurais e os mais diversos grupos de usuários (MORAES, 2012; MAY e GELUDA, 2005).

\section{PAGAMENTO DE SERVIÇOS AMBIENTAIS NO BRASIL}

No início século XXI, com a implementação do Sistema Nacional de Unidades de Conservação (SNUC), em 2000, e do Plano de Ação para a Prevenção e Controle do Desmatamento na Amazônia Legal (PPCDAM), em 2004, o Brasil deu continuidade às políticas de criação de áreas protegidas e ampliou o uso de instrumentos de controle para evitar o desmatamento. Concomitantemente a isso, o país passou a utilizar os PSA como um instrumento para regulação ambiental (VEIGA e GAVALDÃO, 2011; SHIKI e SHIKI, 2011).

A regulamentação dos PPSA no Brasil ocorre muito mais no viés governamental do que pela iniciativa do mercado. Santos e Brito (2012) identificaram oito iniciativas legislativas no âmbito federal (duas leis, dois decretos e quatro PL) e 20 no âmbito estadual (14 leis e seis decretos). Em relação à esfera estadual, as leis, na maioria dos casos, não tratavam

\footnotetext{
${ }^{6}$ Para Moraes (2012, p 44), “o princípio do usuário-pagador (ou poluidor-pagador) estabelece que o beneficiário individual que utiliza um recurso ambiental deverá suportar seus custos, sem imposição de cobrança de taxas abusivas, isentando o setor público e a sociedade destes custos”.
} 
diretamente sobre a criação dos programas de PSA, mas, sim, de normas (SANTOS e BRITO 2012).

Já em âmbito federal, desde 2007, vem sendo discutido no país a criação de um projeto de lei cujo objetivo é instituir a Política Nacional de Pagamento por Serviços Ambientais, Projeto de Lei ${ }^{\circ}$ 792/2007. Esse projeto busca criar o Programa Federal de Pagamento por Serviços Ambientais (ProPSA), o Fundo Federal de Pagamento por Serviços Ambientais (FunPSA) e o Cadastro Nacional de Pagamento por Serviços Ambientais (SANTOS e BRITO, 2012).

De acordo com o que dispõe o Projeto de Lei $n^{\circ} 792 / 2007$, os principais objetivos do Plano Nacional de Pagamento pro Serviços Ambientais são

I - disciplinar a atuação do Poder Público em relação aos serviços ambientais, de forma a manter, recuperar ou melhorar esses serviços em todo o território nacional; II - estimular a conservação dos ecossistemas, dos recursos hídricos, do solo, da biodiversidade, do patrimônio genético e do conhecimento tradicional associado; III - valorizar econômica, social e culturalmente os serviços prestados pelos ecossistemas; IV - reconhecer as iniciativas individuais ou coletivas que favoreçam a manutenção, a recuperação ou o melhoramento dos serviços ecossistêmicos, por meio de remuneração financeira ou outra forma de recompensa; $\mathrm{V}$ - fomentar o desenvolvimento sustentável; VI - promover alternativas de geração de trabalho e renda para populações em situação de vulnerabilidade socioeconômica. (BRASIL, SUBSTITUTIVO AO PROJETO DE LEI N ${ }^{\circ}$ 792, de 2007, p. 3)

A discussão acerca desse projeto de lei é de suma importância para que o Brasil dê um passo adiante no que diz respeito à institucionalização dos programas de pagamento de serviços ambientais. Embora a discussão não tenha avançado muito na esfera federal, nos âmbitos estaduais e municipais, ela está um pouco mais presente. De acordo com Santos e Brito (2012), a maioria dos programas já implementados são regidos por alguma lei ou decreto municipal ou estadual.

No Brasil, o programa Proambiente é considerado a primeira experiência de PSA. Esse programa foi lançado em 2003 e teve suas origens nos debates promovidos pelos movimentos sociais da Amazônia. O projeto tinha por objetivo a promoção do desenvolvimento rural regional, a preservação dos valores socioculturais, promoção de empregos rurais e a conservação do meio ambiente. Apesar disso, o programa foi finalizado em 2010 por falta de recursos e de quadros institucionais no nível federal (SHIKI e SHIKI, 2011).

Os programas de PSA têm sido desenvolvidos, principalmente, no bioma da Mata Atlântica e estão relacionados com a produção de recursos hídricos. De acordo com Veiga e 
Gavaldão (2011), a Agência Nacional de Águas (ANA) tem desempenhado um papel importante na criação de programas de PSA de proteção dos recursos hídricos. Isso se deve, especialmente, ao programa Produtor de Água, criado pela ANA em 2001. Esse programa reconhece o papel dos produtores rurais para geração de serviços ambientais, principalmente os relacionados com a diminuição dos processos de perda de solo e infiltração da água (VEIGA e GAVALDÃO, 2011).

No Brasil, os PPSA hídricos têm ganhado cada vez mais estímulo, primeiramente, porque a proteção desses serviços garante o abastecimento das áreas urbanas. A formação de comitês de bacias hidrográficas e a cobrança pelo uso da água, ainda na década de 1990, também colaboraram para criação desses programas, pois os recursos para o custeio dos programas são geridos pelos próprios comitês de bacia (ELOVOY et. al., 2013).

Atualmente, no Brasil, existem 42 programas de pagamento por serviços ambientais em funcionamento (NOVAES, 2014). Se forem contabilizados os programas que ainda não estão totalmente implementados, esse número sobe ainda mais. Segundo Guedes e Seehusen (2011), até o ano de 2010, somente no bioma da Mata Atlântica existiam mais de 70 programas de PSA, nos mais diversos estágios de implementação, sendo que a maior parte está relacionada com a proteção dos recursos hídricos.

Em seu trabalho, Novaes (idem) mostra que a maioria dos programas de PSA tem como foco principal as modalidades de restrição de uso e de restauração. Esses, em sua maioria, têm entre suas metas e diretrizes a priorização dos agricultores familiares, pequenos produtores e populações tradicionais (NOVAES, 2014).

\section{PENSANDO O PSA PARA ALÉM DA LÓGICA DO MERCADO}

As políticas de PSA têm pautado sua base no discurso de desenvolvimento sustentável proposto pelos países hegemônicos. Dessa forma, o mercado surge como o mediador da relação entre provedores e beneficiários, na medida em que atribui valores aos bens e serviços prestados pelos ecossistemas.

Tal pensamento apresenta incongruências, conforme nos mostra Sachs (2002), pois os mercados não conseguem transcender as visões de curto prazo e não conseguem considerar outra coisa que não seja lucro e a eficiência smithiana de alocação de recursos. Portanto, “o desenvolvimento sustentável é, evidentemente, incompatível com o jogo sem restrições das forças do mercado" (SACHS, 2002, p.55). Moreira (2004, p 3) complementa ao afirmar que “a subsunção da sustentabilidade ao Mercado carrega assimetrias de poderes na distribuição dos valores de troca de mercadorias e serviços, dentre as quais as mercadorias e serviços oriundos dos usos da natureza”. 
A transformação dos serviços ambientais em um bem transacionável do mercado está pautada em uma lógica microeconômica da oferta e da demanda. Contudo, a formação dos preços das mercadorias, no caso dos serviços ambientais, não se dá simplesmente por essa lógica (MATTOS et. al., 2011).

Sachs (2002) considera esse processo de precificação dos recursos naturais uma tentativa por parte dos neoliberais de privatização do capital da natureza e dos serviços ambientais. Para o autor (op. cit.), a utilização dos serviços ambientais como garantia para emissão de títulos de crédito de carbono acaba gerando uma lógica perversa.

Essa lógica perversa é bem explicitada por Mattos (2013), no momento em que ele disserta sobre o funcionamento dos Mecanismos de Desenvolvimento Limpo (MDL).

O maior exemplo desta abordagem é o Mecanismo de Desenvolvimento Limpo (MDL): tenho uma cédula de carbono, sem me preocupar com o que está acontecendo no campo. Se esse crédito se valoriza, eu o guardo; se ele se desvaloriza, eu o vendo e compro debêntures de petróleo, sem uma preocupação real com a questão ambiental. A partir dessa abordagem, em um cenário muito otimista, uma família receberia 2,67 diárias de trabalho por mês, quando sabemos que para eliminar o fogo de um sistema produtivo na Amazônia seriam necessárias cerca de 30 diárias. O que está sendo negociado internacionalmente é o preço do mercado financeiro, a disposição a pagar do mercado, sem levar em consideração o custo de implementação e de transação do agricultor. (MATTOS, 2013, p 23)

O comércio de carbono relacionado com os PSA não só não aliviou a crise climática, como também está gerando impactos para as comunidades. Esses impactos fizeram com que Packer (2013) apontasse, em seu trabalho, questões no que diz respeito aos programas de PSA.

Para Packer (op. cit.), a valoração dos serviços ambientais não pode ser feita sem levar em consideração as demandas e características de cada grupo. A autora critica a valoração baseada no TEEB (A Economia dos Ecossistemas e da Biodiversidade, na sigla em inglês) ou a métrica do carbono. Para ela, o TEEB tenta agregar valor monetário a bens que têm o valor inestimável. Além disso, propõe uma valoração a partir das cadeias produtivas, que, na maioria das vezes, agrega valores externos aos territórios de onde os serviços são prestados.

Packer (2011) utiliza outro exemplo para explicar a relação danosa entre os entes privados na PSA.

Por exemplo, se continuar com o nível de extração X, em dez anos acabará com a água, então, se eu pagar Y para os agricultores a jusante para que eles recomponham a reserva legal e Área de Preservação Permanente (APP), o custo para a cadeia de produção será menor. Essa ação de PSA permite que se libere a emissão de um título em nome da fábrica, que, então, pode agregar valor à sua marca (muitas empresas têm seu capital agregado à 
marca - bem intangível - maior que o capital patrimonial e produtivo, como é o caso da Coca-Cola), como também negociá-lo em bolsas de valores, mercados e futuros. (PACKER, 2011, p.31)

As condicionantes exigidas pelos programas de pagamento de serviços ambientais também são questões que devem ser repensadas. Muitos dos programas de PSA existentes estão relacionados a políticas internacionais de contenção da emissão dos Gases de Efeito Estufa. No Brasil, as políticas de Redução de Emissões por Desmatamento e Degradação Florestal (REDD +) e Bolsa Verde visam à diminuição dos níveis de gases de efeito estufa. Para tal, criminalizam os camponeses por utilizar o roçado e/ou condicionam o pagamento de benefícios à eliminação gradual do uso do fogo. Contudo, essas mesmas políticas facilitam o acesso ao crédito por parte dos grandes agricultores ligados à produção de cana (PACKER, 2011).

Novaes (2014) afirma que os serviços ambientais devem ser analisados sempre de maneira integrada, pois a qualidade de um serviço influencia diretamente a provisão de outro serviço. Um exemplo disso é a manutenção da floresta, que vai influenciar no sequestro de carbono, na produção de água e na biodiversidade. Ademais, os processos resultantes das relações bióticas e abióticas não podem ser desassociados das práticas de manejo utilizadas, ou seja, o trabalho deve ser associado ao uso sustentável (PACKER, 2011; ELOY et. al., 2013; Novaes, 2014).

Outra questão que também merece destaque é que, em boa parte dos programas de PSA, os provedores de serviços são agricultores familiares que se vinculam aos programas de modo voluntário. Contudo, muitas das vezes, esses agricultores não dispõem de renda suficiente para bancarem sozinhos os custos de implantação, manutenção e oportunidade que são necessários para prover esse tipo de serviço. Por isso, faz-se necessário que as entidades públicas, que são financiadoras, destinem parte da verba aos agricultores (MORAES, 2012).

Os métodos de monitoramento e avaliação dos programas de PSA também devem ser repensados, de acordo com Novaes (2014). No Brasil, dos 42 programas avaliados, 30 faziam somente o monitoramento da cobertura vegetal. Segundo Eloy et. al. (2013, p. 29), esse tipo de monitoramento "está ligada à ênfase dada pelo governo às medidas de controle do desmatamento, às expectativas de financiamentos por REDD e às perspectivas de inclusão dos PSA no Código Florestal". Ainda de acordo com os autores, o monitoramento da cobertura vegetal, que, na maioria das vezes, é feito por imagens de satélite, é uma representação binária da paisagem, já que esse tipo de monitoramento não leva em consideração a diversidade de práticas agrícolas nem a percepção dos atores envolvidos.

Destarte, em seu trabalho, Novaes (2012) afirma que, apesar de existirem diversos 
indicadores (qualidade do solo, biodiversidade e sociais) presentes na literatura, ainda não há o incentivo para integração desses indicadores na avaliação dos programas de PSA, especialmente no que diz respeito às conquistas sociais.

Portanto, os principais questionamentos feitos em relação ao PSA têm por objetivo garantir que ele realmente se torne um instrumento para a manutenção do fornecimento dos diversos bens e serviços que são essenciais para o bem-estar dos seres humanos. Dessa forma, Sachs (2002) é bem claro ao afirmar que a atribuição de valores comerciais deve ser evitada. Em vez disso, deve ser ampliada a ideia de bem comum em relação aos recursos naturais, aos seus bens e serviços gerados e aos grandes blocos de conhecimento tecnológico.

\section{CONSIDERAÇÕES FINAIS}

Em um contexto geral, os programas de pagamento por serviços ambientais no Brasil ainda estão se consolidando como política de preservação ambiental e melhoria das condições sociais. Ademais, as discussões acerca da temática devem buscar algo para além do desenvolvimento econômico "sustentável".

O pagamento por serviços ambientais realmente pode vir a colaborar para a diminuição do desmatamento e da degradação dos diversos biomas, desde que as políticas ambientais de comando e controle continuem sendo utilizadas em concomitância a esse instrumento econômico.

A implementação, o desenvolvimento e o monitoramento dos programas de PSA devem ser feitos pelos agentes públicos, e tendo como objetivo a manutenção da qualidade de um bem comum, que é o serviço ambiental.

Apesar das críticas, os programas de pagamento por serviços ambientais podem contribuir para a promoção da sustentabilidade socioambiental. Mas, para tal, é necessário que eles sejam voltados para os pequenos agricultores, para a agricultura familiar e para as populações tradicionais. Mesmo assim, eles não podem ser pensados de cima para baixo, ou seja, os programas devem ser feitos de acordo com as demandas e interesses de cada grupo e de cada territorialidade.

Só assim os PPSA seriam aplicados como instrumentos para garantir a conservação e a melhoria da qualidade de vida dos atores sociais, e não como simples medidas compensatórias.

Por fim, o monitoramento dos programas deve tentar abarcar a integração entre os indicadores ecológicos e sociais, pois só assim será possível avaliar a real potencialidade dos programas de pagamento por serviços ambientais enquanto política socioambiental. 


\section{REFERÊNCIAS BIBLIOGRÁFICAS}

ANDRADE, D. C. ;FASIABEN, M.C.R. . A utilização dos instrumentos de política ambiental para a preservação do meio ambiente: o caso dos Pagamentos por Serviços Ecossistêmicos (PSE). Economia Ensaios (UFU. Impresso), v. 24, p. 113-133, 2009.

ANDRADE, D. C. de ; ROMEIRO, A. R.. Capital natural, serviços ecossistêmicos e sistema econômico: rumo a uma "Economia dos Ecossistemas.Campinas: IE/Unicamp, 2009.

ANA- AGÊNCIA NACIONAL DE ÁGUA, 2009. Programa Produtor de Água: Manual Operativo. Brasília: ANA; SUM p.67

BALVANERA, P. y H. COTLER. 2007. Acercamiento al estudio de los servicios ecosistémicos. Gaceta ecológica, número especial 84-85:8-15.

BOYD, J., BANZHAF, S., 2007. What are Ecosystem services? Ecological Economics 63 (2-3), 616-626.

CHOMITZ, K. M., E. BRENES, and L. CONSTANTINO. 1999. Financing environmental services: the Costa Rica experience and its implications. Science of the Total Environment 240:157-169.

CMMAD, COMISSÃO MUNDIAL SOBRE MEIO AMBIENTE E DESENVOLVIMENTO . Nosso futuro comum. Rio de Janeiro: Fundação Getúlio Vargas, 1991.

COSTANZA, R., D'ARGE, R., DE GROOT, R.S., FARBER, S., GRASSO, M., HANNON, B., LIMBURG, K., NAEEM, S., O’NEILL, R.V., PARUELO, J., RASKIN, R.G., SUTTON, P., VAN DEN BELT, M.,. The value of the world's ecosystem services and natural capital. Nature 387, 253-260. 1997.

DALY, H. E. Crescimento sustentável? Não, obrigado. In: Ambiente e sociedade, ANPPAS, Unicamp, Campinas, vol. VII, n. 2, jul/dez, 2004. p. 197-202.

DAILY, G.C. Nature's Services: Societal Dependence on Natural Ecosystems. Island Press, Washington, DC, 1997.

DE GROOT, R.S., WILSON, M.A.. BOUMANS, R.M.J., A typology for the classification, description, and valuation of ecosystem functions, goods and services. Ecological Economics 41, 393-408. 2002.

DERANI, C.; SOUZA, K. S. S.. Instrumentos econômicos na Política Nacional de Meio Ambiente: por uma economia ecológica. Veredas do Direito (Belo Horizonte), v. 10, p. 07246, 2013.

ELOY, L. ; COUDEL, E. ; TONI, F.. Implementando Pagamentos por Serviços Ambientais no Brasil: caminhos para uma reflexão crítica. Sustentabilidade em Debate, v. 4, p. 21-41, 2013.

FISHER, B., R;. TURNER, K.; and MORLING, P. "Defining and classifying ecosystem services for decision making." Ecological economics 68.3 (2009): 643-653.

FONSECA, D. Discutindo os termos de uma equação de congruência: cultura e desenvolvimento sustentável. In: LIMA, L. C. (Ed.). Em Debate. Revista Eletrônica do Departamento de Serviço Social, PUC-Rio, n. 1, ano 2005. Disponível em <http://www.maxwell.lambda.ele.puc-rio.br>. Acesso em: 04.08.2015

FREITAS, R. de C. M.; NELSIS, C. M. ; NUNES, L. S. A crítica marxista ao desenvolvimento (in)sustentável. Revista Katálysis (Impresso), v. 15, p. 41-51, 2012.

GUEDES, F. B.; SEEHUSEN, S. E. (2011). O PSA na Mata Atlântica - Situação Atual, Desafios e Recomendações In: Pagamentos por Serviços Ambientais na Mata Atlântica: lições aprendidas e desafios. Ministério do Meio Ambiente- MMA, 2011. 280p.

JODAS, N.: PORTANOVA, R. S.. Pagamento por Serviços Ambientais (PSA) e Agroecologia: uma abordagem crítica à agricultura moderna. Revista do Direito Público (Londrina), v. 9, p. 129, 2014. 
LEFF, E.. Educação ambiental e desenvolvimento sustentável. In REIGOTA, Marcos (org.). Verde cotidiano: o meio ambiente em discussão. Rio de Janeiro: DP\&A, 1999 (p.111-129). LEFF, Enrique. Epistemologia Ambiental. 4 ed. São Paulo: Cortez, 2007

LUSTOSA, M.C.J., CÁNEPA, E.M., YOUNG, C.E.F., 2003. Política Ambiental. In: MAY, P.H., LUSTOSA, M.C.J., VINHA, V. Da (org.). Economia do Meio Ambiente. Rio de Janeiro: Elsevier.

MARTÍN-LÓPEZ B., MONTES, CARLOS. Funciones y servicios de los ecosistemas: una herramienta para la gestión de los espacios naturales. In: Guía científica de Urdaibai. UNESCO, Dirección de Biodiversidad y Participación Ambiental del Gobierno Vasco, 2008.

MATTOS, L. Economia do Meio Ambiente e Serviços Ambientais. In: Visões alternativas ao Pagamento por Serviços Ambientais. (Org.).. Núcleo Justiça Ambiental e Direitos - FASE. 1ed. Rio de Janeiro: Fase, 2013, v. , p. 1-80.

MATTOS, L. ; ROMEIRO, A. ; HERCOWITZ, M . Economia do meio ambiente e serviços ambientais: estudo aplicado à agricultura familiar, às populações tradicionais e aos povos indígenas In: Economia do meio ambiente. (Org.).. Mattos, L.; Hercowitz, M.. Brasília-DF: Embrapa, 2011, v. 1,.

MAY, P. H., and L. GELUDA. "Pagamentos por serviços ecossistêmicos para manutenção de práticas agrícolas sustentáveis em microbacias do norte e noroeste do Rio de Janeiro." Anais do VI Encontro da Sociedade Brasileira de Economia Ecológica: o meio ambiente nas políticas públicas (2005).

MEA, MILLENNIUM ECOSYSTEM ASSESSMENT, 2005. Ecosystem and Human WellBeing: Synthesis. Island Press, Washington, DC.

MOREIRA, R. J.. Cultura, sustentabilidade e poderes assimétricos: uma narrativa sobre a renda da natureza na contemporaneidade. In: $\mathbf{2 8}^{\circ}$ Encontro Anual da ANPOCS, Caxambu, 2004.

MONTES, C.;, and SALA, O.. "La Evaluación de los Ecosistemas del Milenio. Las relaciones entre el funcionamiento de los ecosistemas y el bienestar humano." Revista Ecosistemas 16.3 (2007).

MORAES, J. L. A.. Pagamento por Serviços Ambientais (PSA) como Instrumento de Política de Desenvolvimento Sustentável dos Territórios Rurais: O Projeto Protetor das Águas de Vera Cruz, RS. Sustentabilidade em Debate, v. 3, p. 43-56, 2012.

MURADIAN, R. et al. Reconciling theory and practice: An alternative conceptual framework for understanding payments for environmental services. Ecological Economics, v. 69, n. 6, p. 1202-1208, 2010.

NOVAES, R. M. L.. Monitoramento em programas e políticas de pagamentos por serviços ambientais em atividade no Brasil. Estudos Sociedade e Agricultura (UFRRJ), v. 22, p. 408-431, 2014.

OLIVEIRA, L. D.. A geopolítica do desenvolvimento sustentável: reflexões sobre o encontro entre economia e ecologia. Carta Internacional (USP), v. 7, p. 118-139, 2012.

PACKER, L. A. . Não ao PSA, Sim aos Direitos dos Agricultores. In: Visões alternativas ao Pagamento por Serviços Ambientais (Org.).. Núcleo Justiça Ambiental e Direitos - FASE. 1ed.Rio de Janeiro: Fase, 2013, v. , p. 1-80.

PIZZI, J. (2005). O desenvolvimento e suas exigências morais. http://www.ucpel.tche.br/filosofia/vol1/desenvolvimento.pdf. Acesso em: 04.08.2015

PORTO-GONÇALVES, C. W. O Desafio Ambiental. Rio de Janeiro/São Paulo: Editora Record, 2004. v. 1. 179p

PRADO, R. B. . Pesquisas e iniciativas relacionadas à avaliação e manutenção dos serviços ambientais: estado da arte no Brasil. In: XIX Reunião Brasileira de Manejo e Conservação do Solo e da Água, 2012, Lages - SC. XIX Reunião Brasileira de Manejo e Conservação do Solo e da Água, 2012.

RUA, J. . Desenvolvimento, espaço e sustentabilidades. In: JOAO RUA. (Org.). Paisagem, espaço e sustentabilidades: umas perspectiva multidimensional da Geografia. 1ed.RIO 
DE JANEIRO: Ed.PUC-Rio, 2007, v. 1, p. 143-194.

SACHS, I. (2002). Caminhos para o Desenvolvimento Sustentável (4 ${ }^{\mathrm{a}}$ Ed.). Rio de Janeiro: Garamond (96 p.)

SANTOS, P. ; BRITO, B. Propostas de regime legal federal de PSA no Brasil.In: Marco regulatório para pagamento por serviços ambientais no Brasil. 1. ed. Belém: Imazon, 2012. v. 1. 72p .

SAUL, R. P. . O dilema do desenvolvimento no fim do século xx: entre a justiça social e a democracia econômica. In: J. Vicente T. dos Santos; Cesar Barreira; Maíra Baumgarten. (Org.). Crise social e multiculturalismo. 1a.ed.São Paulo: Hucitec, 2003, v. , p. 47-66.

SHIKI, S. ; SHIKI, S. F. N. .Os Desafios de uma Política Nacional de Pagamentos por Serviços Ambientais: lições a partir do caso do Proambiente. Sustentabilidade em Debate, v. 2, p. 99-118, 2011.

VEIGA, F.; GAVALDÃO, M..Iniciativas de PSA de Conservação dos Recursos Hídricos na Mata Atlântica. In: Pagamentos por Serviços Ambientais na Mata Atlântica: lições aprendidas e desafios. Ministério do Meio Ambiente-MMA, 2011. 280p.

WUNDER, S.2005. Payments for environmental services: some nuts and bolts. Center for International Forestry Research (CIFOR), Occasional Paper n. 42.

WUNDER, S., BORNER, J., TITO, M. R., \& PEREIRA, L. (2009). Pagamentos por serviços ambientais: perspectivas para a Amazônia Legal.

Recebido em 21 de julho 2016.

Aceito em 28 de maio de 2017. 